\title{
Food habits of striped hyena (Hyaena hyaena) in a semi-arid conservation area of India
}

\author{
M Shamshad ALAM*, Jamal A KHAN \\ Department of Wildlife Sciences, Aligarh Muslim University, Aligarh 202002, India
}

\begin{abstract}
Striped hyena (Hyaena hyaena) is a near-threatened large carnivore known to occur in arid and semi-arid landscapes in many parts of the world. Its population is declining globally and ecological information is required urgently to meet their conservation needs. We studied the diet pattern of the striped hyena in the semi-arid Gir National Park and Sanctuary (GNPS), western India. Prey items eaten by the striped hyena were identified from scats. Around $44.4 \%$ scats represented single to three mammalian preys while $55.6 \%$ of them represented four preys to seven preys. A variety of food items were identified including mammals, birds, insects and vegetable matters. Scats analysis showed that $63.91 \%$ diet of striped hyena was contributed by wild prey items, $20.94 \%$ by domestic prey and $3.31 \%$ by birds, whereas vegetable and insects contributed $9.92 \%$ and $1.93 \%$, respectively. Diet diversity of the striped hyena computed by the Shannon-Weiner Index $(H)$ was found to be 2.64 . The presence of domestic mammals in the scat remains implied that the striped hyena might frequently visit human habitation in search for food and hence, a potential conflict between human and wildlife might arise. Reducing the dependence of hyena on domestic livestock is a challenge to ensure the survival of striped hyena outside the protected area.
\end{abstract}

Keywords: diet pattern; Gir National Park and Sanctuary; Hyaena hyaena; scat analysis

Citation: M Shamshad ALAM, Jamal A KHAN. 2015. Food habits of striped hyena (Hyaena hyaena) in a semi-arid conservation area of India. Journal of Arid Land, 7(6): 860-866. doi: 10.1007/s40333-015-0007-2

Hyenas, which are carnivorous animals, belonging to the Hyaenidae family are largely found in Africa, Middle East and Indian sub-continents (Ahmed et al., 2012). They generally live in solitary, but have some social organizations (Alam, 2011). In India, only striped hyenas (Hyaena hyaena) are found (Prater, 1980). They have been documented as a near-threatened species by International Union for the Conservation of Nature (IUCN), due to their compromised population size that has shrunk to about $1 \times 10^{4}$ mature individuals throughout their distribution range (Arumugam et al., 2008). Gajera et al. (2009) reported them as the most widespread species in India. They are primarily nocturnal animals that only emerge from their dens after complete darkness and return quickly before sunrise (Kruk, 1976; Alam, 2011).

Several hyenas are scavengers in their habits (Kruk,
1975; Prater, 1980; Macdonald, 1984; Boitani and Bartoli, 1986; Hofer, 1998; Menon, 2003). The striped hyena is considered as a classic scavenger, existing around human settlements and feeding by dried bones, carcasses and also sometimes by fruits, insects and reptiles (Kruk, 1976; Hofer, 1998). As a scavenger, it helps in cleaning the environment (Prater, 1980) and performs function of sanitizing the ecosystem and recycling the precious nutrients like calcium and phosphorus, which are locked up in carcasses of dead animals, by chewing up even the large bones using their specially adapted molars. The morphological structure of hyenas fits for its particular mode of life, which is to feed on prey killed by other animals (Prater, 1980). The striped hyenas are also known for occasional killing of livestock or even humans (Kruk, 1976; Prater, 1980; Hofer, 1998). According to the results

\footnotetext{
*Corresponding author: M Shamshad ALAM (E-mail: msalam01@gmail.com) Received 2014-12-29; revised 2015-03-02; accepted 2015-03-30

(c) Xinjiang Institute of Ecology and Geography, Chinese Academy of Sciences, Science Press and Springer-Verlag Berlin Heidelberg 2015
} 
of Kruk (1976), striped hyena was more omnivorous than spotted hyenas (Crocuta crocuta), scavenging a great variety of food items. There are also reports of attacks by striped hyena on sheep, goat and donkey in North Africa, Israel, Iran, Pakistan and India, on horse in Iran and on dogs in India (Hofer, 1998).

In many areas of their geographical distributions, there is documented case of injuries to adults sleeping outside, snatching and killing of children (East and Hofer, 1998) and grave robbery (Kruk, 1976; East and Hofer, 1998). In Maharashtra (Sholapur) India, carcasses of sheep, goat, buffalo, cow, domestic cat and dogs were observed from a single den of striped hyena (Alam, 2011). Striped hyenas also occasionally cause damage to date palms in date plantation (Hofer, 1998), fields of melons, water melons, grapes, apricots, peaches and cucumber and around the house in Serengeti forests where often seen to feed on domestic refuses such as various kinds of fruits, bread, boiled potatoes and animal offal such as bones, pieces of leather, etc (Kruk, 1976).

Striped hyena is one of the important carnivorous animals found in Gir National Park and Sanctuary (GNPS) including Asiatic lions (Panthera leo persica) and leopard (Panthera pardus) (Meena and Kumar, 2012). Alam (2011) reported a total of 28 dens and 30 resting sites of striped hyena in GNPS, thus confirming the existence of this species in the area. However, little study on striped hyenas of GNPS had been done to obtain their ecological information for the long-term management planning. Therefore, the purpose of the study was to minimize this gap through investigating the food habits and preference of this species in GNPS.

\section{Materials and methods}

\subsection{Study area}

GNPS lies $40 \mathrm{~km}$ from the coast in the Kathiwar Peninsula also known as Saurasthtra Peninsula of Gujarat

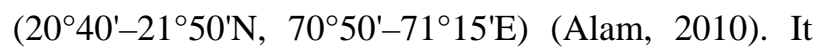
stretches over a length of about $70 \mathrm{~km}$ from west to east and $40 \mathrm{~km}$ from north to south. The total area of GNPS extends to $1,412.13 \mathrm{~km}^{2}$ of which the national park comprises of $258.71 \mathrm{~km}^{2}$ and sanctuary is surrounded by $1,153.41 \mathrm{~km}^{2}$ (Fig. 1).
GNPS has the core population of Asiatic lion of the world in the Asiatic Lion Landscape (ALL), Gujarat (Pandey et al., 2014). It is also a resort of many threatened and rare species. Total 600 flowering plant species, 39 species of mammals, 26 species of reptiles, more than 300 species of birds and around 2,000 species of insect were recorded in GNPS (Meena and Kumar, 2012).

Undulating hills in GNPS extend one after another in all directions. The altitude ranges from $152 \mathrm{~m}$ in western part of Gir to $648 \mathrm{~m}$ at Sarkala hill near Chachia Pania. Small streams flow through the entire GNPS that ultimately join major rivers. Gir forms major catchments from 8 different rivers of which 4 rivers have been dammed. The rivers are Hiran, Shingavade, Machundri, Raval, Malan, Dhatardi, Shetrungi and Popatedi, respectively (Alam et al., 2014). According to the classification of forest type (Champion and Seth, 1968), the study area belongs to the type of $5 \mathrm{~A} / \mathrm{Cia}$, i.e. very dry teak forests. Teak occurs mixed with dry deciduous species. Composition of important tree species in GNPS in descending order is Tactona grandis (31.3\%), Wrightia tinctoria (11.2\%), Acacia catechu (9.2\%), Zizyphus mauritiana (7.5\%), Acacia nilotica (4.2\%), Anogeissus latifolia (3.9\%), Acacia leucophloea (3.4\%), Terminalia crenulata (3.1\%), Diospyrosmel anoxylon (2.4\%), Bauhinia purpurea (2.4\%), Grewiati liaefolia (1.9\%), Acacia ferruginea (1.8\%), Boswellia serrata (1.7\%), Lannea corromandelica (1.5\%), and Butea monosperema (1.3\%) (Khan et al., 1996; Sharma and Johnsingh, 1996).

The climatic condition of GNPS is generally hot with irregular monsoon. Seasons are fairly distinct with monsoon ranging from June to September, followed by a post-monsoon season. Winters arrive in late November which ends up to early March. Winters were followed by a hot dry season starting from March to June. The temperature ranges between $7^{\circ} \mathrm{C}-44.4^{\circ} \mathrm{C}$ with unpredictable and irregularly rainfall. Eastern portion of GNPS is more arid than western part. Around 45 small settlements known as nesses are occupied by maldharis throughout GNPS (Meena and Kumar, 2012). 


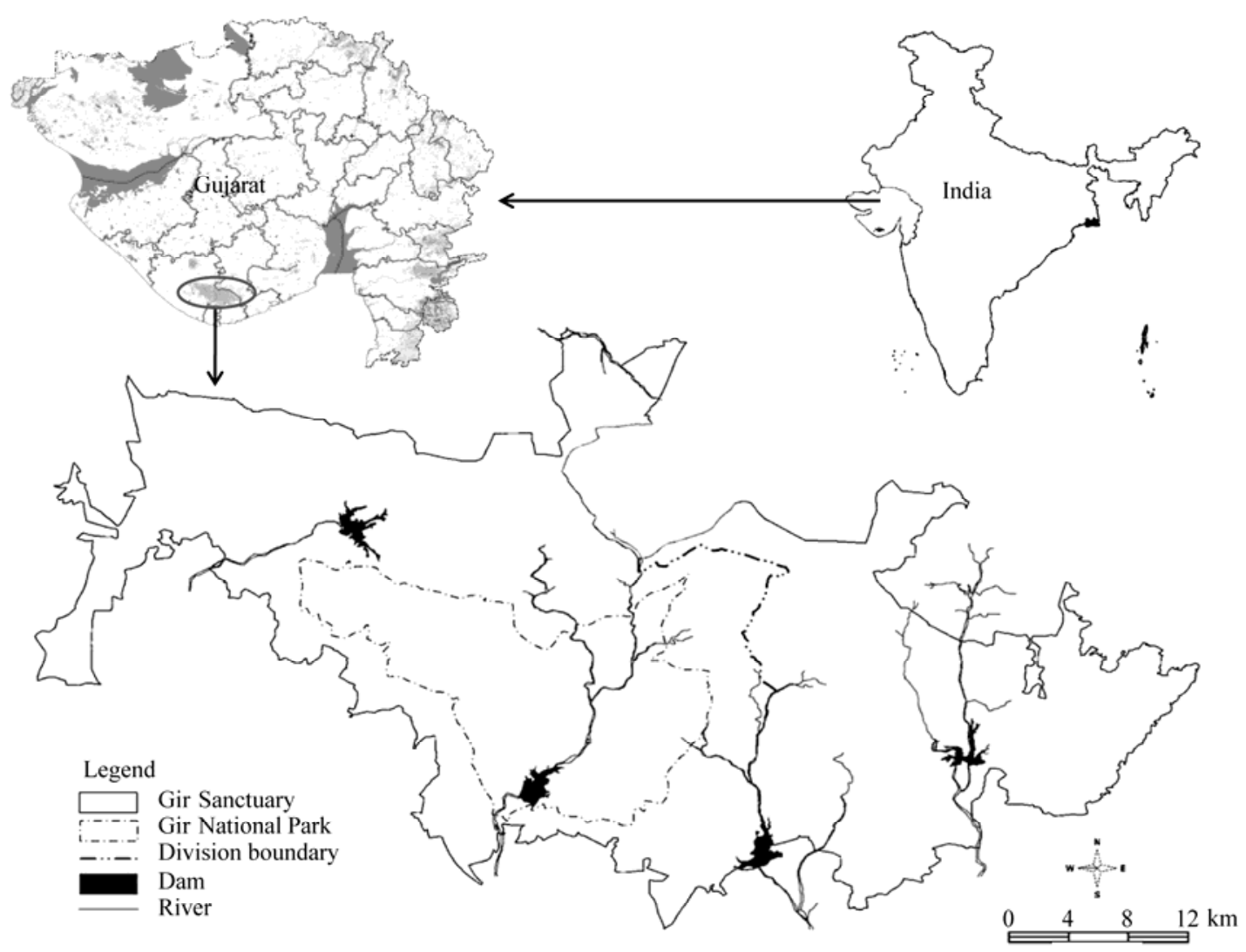

Fig. 1 The location map of Gir National Park and Sanctuary, Gujarat, India

\subsection{Methods}

It is difficult to determine each prey item which contributes to the diet of hyena by direct observation in the field. Scat analysis method is thus widely used for studying food habits of carnivores as it is a non-invasive technique and scats are easily to be collected and analyzed (Korschgen, 1980; Litavaitis et al., 1996; Alam et al., 2015). The scats of striped hyenas were collected from active dens from February to June of 2006 during the study period. And the scats are very easy to be identified since they are white, pellet-like resemble camel dung (Kruk, 1975; Alam, 2006; Alam, 2011), however, scats of young hyena like small pallet and the color is dark brown to black (Alam, 2011). Size, color and location of scats were the main parameters to differentiate between adult and young heynas. We also collected regurgitated hair ball of hyena from den sites. Both scats and regurgitated hair balls were collected near the dens and stored in poly bags, while food remains near the dens were also recorded.

Scats and hair balls were washed on a sieve under running water and indigestible prey remains such as hairs, bones, claws, hoofs, teeth, feathers and other materials were used for identification of prey species (Lockic, 1959; Korschgen, 1980; Jhala, 1993; Mukherjee et al., 1994a, b; Litvaitis et al., 1996; Jethva and Jhala, 2003; Majumder et al., 2011). Hairs are the most important factors used to determine the prey species in the scats (Lockic, 1959; Korschgen, 1980). Hairs were collected randomly from each sample and treated with xylol and subsequently with xylene. Then, a total of 30 hairs were picked up randomly from each scat or hair balls for slide preparation. The mounted slides were examined using a compound stereoscopic microscope (Olympus CH 20i) under 40X magnification. The microscopic examination of hairs and their characteristics such as medullary and cuticular patterns were recorded and compared with reference slides. 
Percentage occurrence of a prey item was calculated as the number of times a specific prey item was found to occur in scat and expressed as a percentage of all prey occurrences (Floyed et al., 1978; Weaver and Hoffman, 1979; Ackerman et al., 1984). The frequency of occurrence of prey species in the scats was computed as the number of occurrence of each prey type divided by the total numbers of scats analyzed and expressed as percentage (Leopold and Krausman, 1986; Corbett, 1989; Reynold and Aebischer, 1991; Jethva and Jhala, 2004). Variability in food habits of striped hyenas was computed by using Shannon-Weiner Index $(H)$ (Fowler et al., 2006):

$$
H=-\sum p_{i}\left(\ln p_{i}\right) \text {. }
$$

Where, $p_{i}$ is the proportion of the $i^{\text {th }}$ species in the samples. All quantitative data were transformed to ensure that all the variables were distributed normally following Fowler et al. (2006).

\section{Results}

Eighty two scats of striped hyenas from GNPS showed that $34.6 \%$ of scats represented three prey items, $27.2 \%$ represented four preys, $21.0 \%$ represented five preys, $4.9 \%$ represented single to double prey items and $3.7 \%$ represented six and seven prey items, respectively (Fig. 2). A total of 12 regurgitated hairballs were analyzed which indicated that 33.3\% represented four prey items, $25.0 \%$ represented three prey items, $16.7 \%$ represented five prey items and 8.3\% represented single, double and six prey items (Fig. 3).

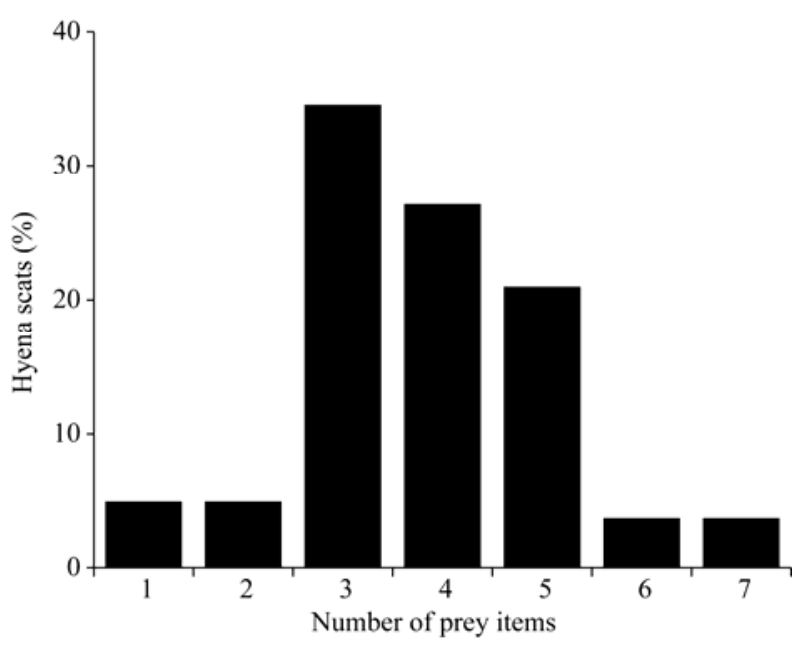

Fig. 2 Percentage of prey items in the hyena scats $(n=82)$

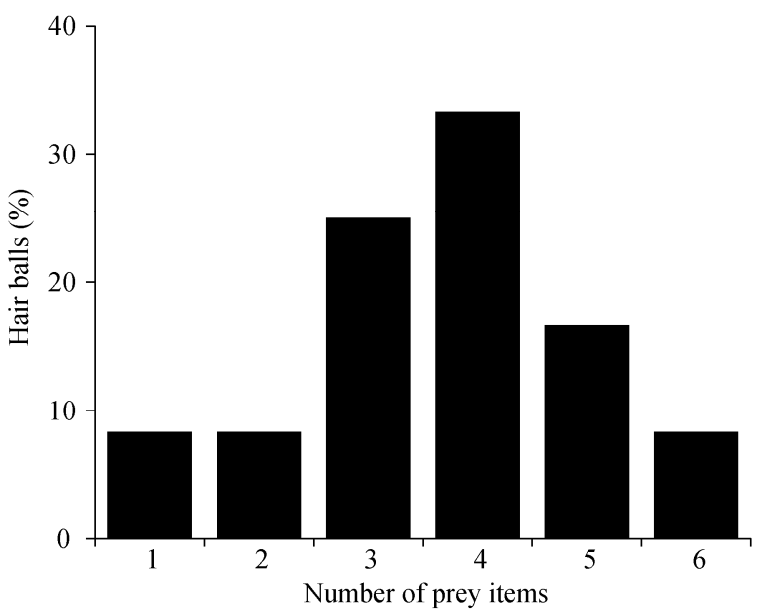

Fig. 3 Percentage of prey items in the regurgitated hairballs $(n=12)$

The variability of food items in the diet of striped hyena was identified which included mammals, birds, insects as well as vegetable matters (fruits). In the diet of striped hyena large mammals contribute much part of the food requirement. Contribution of small mammals (hares, squirrel, civets and rodents) was found to be $40.2 \%$ and $38.5 \%$ in scats and hairballs, respectively. Wild mammal preys contributed $63.9 \%$, while domestic mammals were $20.9 \%$ in the diets of hyena (Table 1). Result of chi-squire test (Table 2) indicated that there was no significant difference in the diets of adult and young striped hyena except in the fruit of Zizyphus spp. $(P<0.01)$. On the whole, diet diversity of food items of striped hyenas was computed by the Shannon-Weiner Index $(H)$. The overall diversity of food item of striped hyena was 2.64 in GNPS.

\section{Discussion and conclusion}

Food habit is one of the important aspects of the animal ecology. Among the carnivores, scavengers have specialized food habit which is crucial for long-term management planning. As the striped hyenas are large carnivores and scavengers, very little information is available about their feeding ecology and habits. These animals feed on the preys killed by the other animals as well as naturally dead animals (Kruk, 1975, 1976; Prater, 1980; Macdonald, 1984; Boitani and Bartoli, 1986; Hofer, 1998; Jhala, 2002; Sinha, 2004). Striped hyenas are also known as an omnivorous animal thus, feed on a variety of food items ranging from animal to vegetable materials (Kruk, 1976). 
Table 1 The percentage occurrence of food items of striped hyenas from the analysis of scats $(n=82)$ and hairballs $(n=12)$

\begin{tabular}{|c|c|c|}
\hline \multirow{2}{*}{ Food item } & \multicolumn{2}{|c|}{ Percentage of occurrence (\%) } \\
\hline & Scat & Hair ball \\
\hline Chital (Axis axis) & $7.71 \pm 0.38$ & $7.69 \pm 1.00$ \\
\hline Sambar (Rusa unicolor) & $14.33 \pm 0.73$ & $13.46 \pm 1.81$ \\
\hline Wildboar (Sus scrofa) & $1.38 \pm 0.04$ & $1.92 \pm 0.19$ \\
\hline Langur (Semnopithecus entellus) & $0.28 \pm 0.00$ & - \\
\hline Hare (Lepus nigricollis) & $14.33 \pm 0.73$ & $15.38 \pm 2.08$ \\
\hline Squirrel (Funambulus palmarum) & $8.54 \pm 0.42$ & $1.92 \pm 0.19$ \\
\hline Civet (Viverricula indica) & $6.61 \pm 0.32$ & $3.85 \pm 0.46$ \\
\hline Rodents & $10.74 \pm 0.54$ & $17.31 \pm 2.35$ \\
\hline Buffalo (Bubalus arnee) & $14.05 \pm 0.71$ & $11.54 \pm 1.54$ \\
\hline Cow (Bos primigenius) & $6.34 \pm 0.31$ & $7.69 \pm 1.00$ \\
\hline Dog (Canis lupus familiaris) & $0.55 \pm 0.00$ & $3.85 \pm 0.46$ \\
\hline Peafowl (Pavo cristatus) & $1.93 \pm 0.07$ & $1.92 \pm 0.19$ \\
\hline Unidentified birds & $1.38 \pm 0.04$ & $1.92 \pm 0.19$ \\
\hline Insects & $1.93 \pm 0.07$ & - \\
\hline Fruits & $6.06 \pm 0.29$ & $1.92 \pm 0.19$ \\
\hline Grass & $3.86 \pm 0.17$ & $9.62 \pm 1.27$ \\
\hline
\end{tabular}

Note: Mean \pm SE - indicates the missing data.

Table 2 The food item contents of 44 scats of adult and 38 scats of young striped hyenas from GNPS, Gujarat, India

\begin{tabular}{|c|c|c|c|}
\hline \multirow{2}{*}{ Prey item } & \multicolumn{2}{|c|}{ Percentage of scats containing remains (\%) } & \multirow{2}{*}{ Chi-squares value } \\
\hline & Adult & Young & \\
\hline Chital (Axis axis) & 43 & 23 & $3.57, P>0.05$ \\
\hline Sambar (Rusa unicolor) & 65 & 60 & $0.69, P>0.05$ \\
\hline Hare (Lepus nigricollis) & 70 & 55 & $1.92, P>0.05$ \\
\hline Dog (Canis lupus familiaris) & 4 & 0 & $2.00, P>0.05$ \\
\hline Buffalo (Bubalus arnee) & 59 & 65 & $0.02, P>0.05$ \\
\hline Cow (Bos primigenius) & 29 & 26 & $0.39, P>0.05$ \\
\hline Civet (Viverricula indica) & 31 & 26 & $0.67, P>0.05$ \\
\hline Squirrel (Funambulu spalmarum) & 50 & 23 & $5.45, P<0.05$ \\
\hline Wildboar (Sus scrofa) & 11 & 0 & $5.00, P<0.05$ \\
\hline Langur (Semnopithecus entellus) & 0 & 2 & $1.00, P>0.05$ \\
\hline Peafowl (Pavo cristatus) & 4 & 13 & $1.29, P>0.05$ \\
\hline Rodents & 40 & 55 & $0.23, P>0.05$ \\
\hline Unidentified birds & 6 & 5 & $0.20, P>0.05$ \\
\hline Insects & 9 & 7 & $0.14, P>0.05$ \\
\hline Zizyphus spp. & 12 & 0 & $12.00, P<0.01$ \\
\hline Unidentified fruits & 18 & 5 & $3.60, P>0.05$ \\
\hline Grass & 22 & 10 & $2.57, P>0.05$ \\
\hline
\end{tabular}

Number of prey items detected in a scat showed variation among the diets of striped hyenas. This vari- ation in diet of striped hyena could be due to its scavenging habit as generalist feeders. Due to scavenging 
behavior, these species encounter limitations in the availability of carcasses, which they may feed on small mammals, insects, birds and vegetable materials especially fruits. Prey items of small mammals, insects and fruits of the striped hyena had also been reported (Kruk, 1976; Wagner, 2006; Alam, 2011). The diet of striped hyena in Serengeti includes buffalo (very large mammals), zebra, wild beast, kongoni, topi (large mammals), Grant's gazella, Thomson's gazella, impala (medium sized mammals), dikdik, hare, springhare (small mammals), rodents, shrew (very small mammals), lizard, snake, tortoise (reptiles) and birds, insects, vegetable (like Balanites aegyptica fruit) in Serengeti forests, where they prefer more small mammals species (Kruk, 1976). However, the diet of striped hyena in GNPS differs from its counterpart from Africa. On the basis of present study, their diets consist of sambar, chital, buffalo, cow, hare, rodent, civet, squirrel, wildboar, langur, dog, peafowl, birds, insects, fruits and grasses. It is suggested that availability of food items in the geographical distribution range governs the diet pattern of a species. However, the prey group of small mammals continues to support the diet of striped hyenas in the distant geographic distribution range.

Result of scat analysis indicated that hyena prefers more sambar and hare followed by livestock (buffalo) and others food items like rodents, birds and fruits also play important role in the diet. At GNPS, the hyena depended on both wild animals as well as livestock because the forest supports a good number of wild herbivores population and livestock of pastoralists and an extraordinary number of predators which predate on these preys and make available to striped hyena in form of carcass leftovers.

While comparing the diets of adult and young striped hyenas, there is no significant difference in the diet except in the fruit of Zizyphus spp. The reason behind may be due to the unavailability of food items or possibly the mother hyena is not able to carry the food items to the den as young ones are fed by adults. Non-availability of Zizyphus spp. to young hyenas at dens sites explains the differences with adult hyenas. It is also impossible for the adult hyenas to provide every food item which they are eating to their young ones. A number of food remains near the dens include chital (skull, legs, bones), wildboar (skull, bones), buffalo (skin and bones), cow (skin and bones), peafowl (feathers), etc. This suggests that the younger generations can't digest hard bones, skins, feathers unlike their adults.

Present study was performed during the seasons of winter and summer in the semi-arid Gir forest. It is therefore, suggested that the reported results may vary in different seasons because the availability of food items and food preference will be changed. In conclusion, the primary food of the striped hyena was consisted of large to medium size mammals, and rodents including the Indian hare as well as plant material (mainly fruits) in GNPS. The presence of domestic mammals in the scat remains also revealed that striped hyena frequently visited human settlements in search of food and hence a potential conflict between human and wildlife will occur if the wild food resources of this species depleted in their activity range especially outside the protected areas. Hence, maintenance and preservation of prey abundance for striped hyena is necessary in avoiding the human-wildlife conflict in this area. It is also suggested that ecological protection of this large carnivore at a larger scale is needed for finding enough diets and temporal activity for resource partitioning patterns as well as ecological sympatry.

\section{Acknowledgements}

Financial support has been provided by the Ministry of Environment \& Forests, Government of India. We are grateful to the Gujarat State Forest Department for permission to carry out this study, and we are thankful to the Department of Wildlife Sciences, Aligarh Muslim University for logistic and institutional support. Field assistants Dost MOHAMMAD and Suresh DARBAR are also acknowledged for their help in field work.

\section{References}

Ackerman B B, Lindzey F G, Hernker T P. 1984. Cougar food habits in southern Utah. Journal of Wildlife Management, 48: 147-155.

Ahmed F A M, Takona N Y, Yousif R A, et al. 2012. Some behavioral traits of striped hyena under captive conditions. Journal of Life Sciences Biomed, 2(5): 196-199.

Alam M S. 2006. Ecological studies on striped hyena (Hyaena hyaena), in Gir NP \& Sanctuary. MSc Thesis. Aligarh: Aligarh Muslim University.

Alam M S. 2010. First record of lesser false vampire bat (Magaderma 
spasma) in Gir National Park \& Sanctuary. Journal of the Bombay Natural History Society, 107(2): 155-156.

Alam M S. 2011. Status ecology and conservation of striped hyena (Hyaena hyaena) in Gir National Park and Sanctuary, Gujarat. PhD Dissertation. Aligarh: Aligarh Muslim University.

Alam M S, Khan J A, Pathak B J, et al. 2014. Assessment of forest density using geospatial techniques of a tropical protected area. International Journal of Scientific and Research Publications, 4(3): $1-6$.

Alam M S, Khan J A, Nogoroje C H, et al. 2015. Food preference of golden jackal Canis aureus in Gir National Park and Sanctuary, Gujarat. Journal of Threatend Taxa. 7(2): 6927-6933.

Arumugam R, Wagner A, Mills G. 2008. Hyaena hyaena. In: IUCN Red List of Threatened Species. Version 2. [2014-03-20]. http://www.iucnredlist.org.

Boitani L, Bartoli S. 1986. The Mac Donald Encyclopedia of Mammals. London: Mac Donald \& Co. Ltd.

Champion H G, Seth S K. 1968.A Revised Survey of the Forest Types of India. New Delhi: Governmental of Indian Press, 404.

Corbett L K. 1989. Assessing the diet of dingoes from feces: a comparison of three methods. Journal of Wildlife Management, 53(20): 528-532.

East M L, Hofer H. 1998. Cultural and Public Attitudes: Improving the Relationship between Human and Hyaenas. Status Survey \& Conservation Action Plane; IUCN/SSC. Oxford: Information Press.

Floyed T G, Mech L D, Jordan P J. 1978. Relating wolf scat content to prey consumes. Journal of Wildlife Management, 42: 528-532.

Fowler J, Cohen L, Jarvis P. 2006. Practical Statistics for Field Biology. England: Jhon Wiley \& Sons, 259.

Gajera N, Dave S M, Dharaiya N. 2009. Feeding patterns and den ecology of striped hyena (Hyaena hyaena) in North Gujarat, India. Tiger Paper, 36(1): 13-17.

Hofer H. 1998. Species Accounts, Status survey \& Conservation Action Plan of Hyaena. Oxford: Information Press.

Jhala Y V. 1993. Predation on blackbuck by wolves in Velavdar National Park, Gujarat, India. Conservation Biology, 4: 874-881.

Jethva B D, Jhala Y V. 2003. Sample size consideration for food habits studies of wolfs from scats. Mammalia, 68(4): 589-591.

Jethva B D, Jhala Y V. 2004. Foraging ecology, economics and conservation of Indian wolves in the Bhal Region of Gujarat, Western India. Biological Conservation, 116: 351-357.

Khan J A, Chellam R, Rodgers W A, et al. 1996. Ungulate density and biomass in the tropical dry deciduous forest of Gir, Gujarat, India. Journal of Tropical Ecology, 12:149-162.

Korschgen L K. 1980. Procedure for food habits analysis. In: Schemnitz S D. Wildlife Management Techniques Manual. Washington DC:
The Wildlife Society, 113-128.

Kruk H. 1975. Hyaena. Great Britain: Oxford University Press.

Kruk H. 1976. Feeding and social behavior of the striped hyaena ( $H y-$ aena hyaena). East African Wildlife Journal, 14: 91-111.

Leopold B D, Krausman P R. 1986. Diet of 3 predators in Big Bend National Park, Texas. Journal of Wildlife Management, 50: 290-295.

Lockic J D. 1959. The estimating of the food of Foxes. Journal of Wildlife Management, 23(2): 224-231.

Litvaitis J A, Kimberly T, Anderson E M. 1996. Measuring Vertebrate use of terrestrial habitats and foods. In: Bookhout T. A. Research and Management Techniques for Wildlife and Habitats. Bethesda: The Wildlife Society, 254-274.

Macdonald D. 1984. The Encyclopedia of Mammals. London: Greenwich Editions, 154-159.

Majumder A, Sankar K, Qureshi Q, et al. 2011. Food habits and temporal activity patterns of the golden jackal Canis aureus and the jungle cat Felischaus in Pench Tiger Reserve, Madhya Pradesh, India. Journal of Threatened Taxa, 3 (11): 2221-2225.

Meena R L, Kumar S. 2012. Management Plan for Gir Protected Areas, Vol. I. Gujarat: Gujarat Forest Department.

Menon V. 2003. A Field Guide to Indian Mammals. Singapore: Christopher Helm Publishers Ltd, 200.

Mukhergee S, Goyal S P, Chellam R. 1994a. Standardization of scat analysis techniques for the leopard Panthera pardus in Gir NP, Western India. Mammalia, 58: 139-143.

Mukhergee S, Goyal S P, Chellam R. 1994b. Refined techniques for the analysis of Asiatic lion (Panthera leo persica) scats. Acta Theriologica, 39(4): 425-430.

Pandey C N, Meena R L, Kumar S, et al. 2014. Action Plan for the Conservation of the Asiatic Lion (Panthera leo persica Mayer, 1826). Gujarat: Gujarat Forest Department, 72.

Prater S H. 1980. The Book of Indian Animals. Bombay Natural History Society. Bombay: Oxford University Press.

Reynold J C, Aebischer N J. 1991. Comparison and quantification of carnivore diet by fecal analysis: a critique, with recommendation, based on study of the fox Vulpes vulpes. Mammal Review, 21(3): 97-122.

Sharma D, Johnsingh A J T. 1996. Impact of management practices on lion and ungulate habitats in Gir PA, WII. In: Qureshi Q, Shah N. 2004. Vegetation and Habitat Monitoring. Monitoring of Gir. Gujarat Forest Department Technical Reports Wildlife Institute of India, Dehar Dun.

Sinha B K. 2004. Mammals of Gujarat. Gujarat: Jan Sampark Department.

Wagner A P. 2006. Behavioral ecology of striped hyena (Hyaena hyaena). PhD Dissertation. Montana: Montana State University.

Weaver J L, Hoffman S W. 1979. Differential delectability of rodents in the coyote scats. Journal Wildlife Management, 43: 783-789. 